Ciência Florestal, Santa Maria, v. 23, n. 1, p. 89-98, jan.-mar., 2013

ISSN 0103-9954

\title{
CALAGEM E ADUBAÇÃO FOSFATADA NO CRESCIMENTO DE MUDAS DE Mimosa caesalpiniifolia Benth. EM LATOSSOLO VERMELHO-AMARELO
}

\author{
LIMING AND PHOSPHATE FERTILIZER ON GROWTH OF Mimosa caesalpiniifolia Benth. \\ SEEDLINGS IN RED-YELLOW LATOSOL
}

\author{
Raimundo Tomaz da Costa Filho ${ }^{1}$ Sérgio Valiengo Valeri ${ }^{2}$ Mara Cristina Pessôa da $\mathrm{Cruz}^{3}$
}

\begin{abstract}
RESUMO
O presente trabalho teve por objetivo avaliar os efeitos da adição de calcário e adubo fosfatado na produção de mudas de sabiá (Mimosa caesalpiniifolia Benth.) sem acúleos, em ambiente protegido. Plântulas com 10 dias de idade foram transferidas para sacos de plástico contendo 2,0 kg de Latossolo Vermelho-Amarelo distrófico psamítico, coletado na camada de 40 a $70 \mathrm{~cm}$. O experimento foi conduzido no município de Teresina - PI, no período de julho a outubro de 2008 , em ambiente protegido por tela com $50 \%$ de retenção de luz. Foram usadas duas doses de calcário (com e sem calcário) e cinco doses de fósforo, combinadas em esquema fatorial $2 \times 5$. O delineamento experimental foi em blocos ao acaso com quatro repetições e cada parcela continha três mudas. A quantidade de calcário foi calculada para elevar a saturação por bases a $50 \%$ com o uso de calcário e as doses de fósforo foram 0, 30, 60, 90 e $120 \mathrm{mg} \mathrm{kg}^{-1} \mathrm{de}$ P. Foi cultivada uma muda por saco de plástico, com as dimensões de $10 \times 23 \mathrm{~cm}$. As variáveis avaliadas nas mudas foram: altura, diâmetro a $1,0 \mathrm{~cm}$ do coleto, área foliar, número de folhas e matéria seca da parte aérea e raízes. Nas condições do solo estudado, a calagem não é necessária para produção de mudas de sabiá. A aplicação de, em média, 72 a $107 \mathrm{mg} \mathrm{kg}^{-1}$ de $\mathrm{P}$ obtém-se, respectivamente, de 90 a $100 \%$ dos máximos rendimentos de altura, diâmetro, área foliar, biomassa da parte aérea e raízes.
\end{abstract}

Palavras-chave: sabiá; espécie madeirável; fertilização; calcário.

\section{ABSTRACT}

This work aimed to evaluate the effects of liming and phosphate fertilizer for the production of sabiá (Mimosa caesalpiniifolia Benth.) seedlings without thorns under a greenhouse. Seedlings 10 days old were transferred to plastic bags containing $2.0 \mathrm{~kg}$ of psamitic Dystrophic Red-Yellow Latosol (Typic Haplustox) collected from 40 to $70 \mathrm{~cm}$ layer. The experiment was carried out in Teresina county, Piauí state, Brazil, from July to October of 2008. Two liming doses (with and without liming) and five phosphorus doses combined in a 2 x 5 factorial scheme were used. The experimental design used was the randomized blocks with four replications having each plot three seedlings. The calculated lime amount was enough to elevate the base saturation to $50 \%$ and the phosphorus doses were: $0,30,60,90$, and $120 \mathrm{mg} \mathrm{kg}^{-1}$ of soil. One seedling per pot was cultivated and the pot dimension was 10 by $23 \mathrm{~cm}$. The evaluated variables were height, diameter, leaves number, leaf area, and shoot and roots dry matter. For the studied soil condition, the liming is not necessary to produce 'Sabiá' seedlings. The application, on average, from 72 to $107 \mathrm{mg} \mathrm{kg}^{-1}$ of $\mathrm{P}$ promote, respectively, from 90 to $100 \%$ of maximum values of height, diameter, leaf area and shoots and roots biomass.

Keywords: 'Sabiá'; woody species; fertilization; lime.

1. Engenheiro Florestal, Dr., Professor Adjunto, Departamento de Fitotecnia, Universidade Federal do Piauí, Centro de Ciências Agrárias, Campus Universitário Ministro Petrônio Portella, CEP 64049-550, Teresina (PI). tomaz@ufpi.br

2. Engenheiro Florestal, Dr., Professor Titular do Departamento de Produção Vegetal, Universidade Estadual Paulista, Faculdade de Ciências Agrárias e Veterinárias, Via de Acesso Prof. Paulo Donato Castellane, km 5, CEP 14884-900, Jaboticabal (SP). Bolsista de Produtividade do CNPq. valeri@fcav.unesp.br

3. Engenheira Agrônoma, Dr ${ }^{a}$., Professora Assistente do Departamento de Solos e Adubos, Universidade Estadual Paulista, Faculdade de Ciências Agrárias e Veterinárias, Via de Acesso Prof. Paulo Donato Castellane, km 5, CEP 14884-900, Jaboticabal (SP). mcpcruz@fcav.unesp.br

Recebido para publicação em 22/04/2010 e aceito em 27/03/2012 


\section{INTRODUÇÃO}

Mimosa caesalpiniifolia Benth., pertencente à família Fabaceae-Mimosoideae, conhecida como sabiá, ou sansão-do-campo, é uma espécie florestal de grande potencial para a região Nordeste. É uma espécie pioneira que ocorre naturalmente entre as latitudes de $2^{\circ} 30^{\prime} S$ no Maranhão, a $15^{\circ} 20^{\prime} S$ em Minas Gerais, tanto em formações primárias como secundárias, onde é comum ou frequente nas capoeiras. A árvore é explorada como fonte de madeira, em decorrência de sua alta resistência físicomecânica, com uma variação de moderadamente densa a densa, respectivamente de 0,80 a $1,10 \mathrm{~g} \mathrm{~cm}^{-3} \mathrm{e}$ alto poder calorífico, com $73 \%$ de carbono fixo, e teor de cinzas de 1,8\% (RAMALHO, 2007). O carvão tem alto poder calorífico, destacando-se o seu elevado rendimento gravimétrico (32\%), baixo teor de cinza $(1,71 \%)$ e alto rendimento em carbono fixo, em torno de $25 \%$ (GONÇALVES et al., 1999). É também recomendada para uso direto como fonte primária de energia, produzindo ótima lenha (PAULA, 1980). A porcentagem de carbono fixo é em torno de $73 \%$. A madeira é usada para produção de estacas, mourões e dormentes, lenha e carvão como alternativa energética. As folhas podem ser usadas como forragem, pelo seu elevado valor nutritivo, com $17 \%$ de proteína bruta (BRAGA, 1976). Por ser uma espécie de crescimento rápido e resistente à seca, é usada para recuperação de áreas degradadas (LORENZI, 2000).

O ambiente edáfico de ocorrência natural do sabiá caracteriza-se por solos arenosos, profundos, com baixa capacidade de retenção de água, acidez elevada, baixos teores de nutrientes e matéria orgânica (MENDES, 1989). Por sua baixa exigência em fertilidade e umidade dos solos, desenvolve-se bem, inclusive em áreas muito degradadas, onde tenha havido movimentação de terra e exposição do subsolo (RAMALHO, 2007). Entretanto, nesses casos, é importante suprir as plantas, por meio de adubação orgânica ou química, para obter melhores resultados em termos de produção de madeira (RIBASKI et al., 2003). O sabiá ocorre naturalmente em terrenos profundos, principalmente em solos de textura arenosa. Essas classes de solo distribuem-se em áreas de relevo plano no Estado do Piauí, com a paisagem de vegetação primária e secundária representada predominantemente por palmáceas (babaçu, tucum e carnaúba) associadas com formações florestais subcaducifólias (floresta/ cerrado) e espécies da caatinga, dentre as quais o sabiá (JACOMINE, 1986).

A qualidade das mudas de espécies florestais nativas é imprescindível para sua sobrevivência após o plantio no campo, bem como para efetivação dos reflorestamentos e práticas de enriquecimento de ecossistemas florestais degradados. $\mathrm{O}$ uso de mudas de qualidade também diminui a frequência dos tratos culturais de manutenção do povoamento recém-plantado, reduz os custos de implantação e aumenta o incremento volumétrico corrente anual (CARNEIRO, 1995). Portanto, vários estudos são desenvolvidos para promover o crescimento e aumentar a qualidade das mudas. Entre as variáveis de interesse científico estudadas na formação das mudas são os recipientes e substratos. Houve uma evolução no uso de recipientes e os mais usados são de pequenas dimensões e os substratos são leves. Entretanto, os sacos de plásticos ainda são usados, principalmente para formação de mudas de espécies nativas. Quando se opta por recipientes desse tipo, o solo ainda é uma opção como substrato para a formação das mudas (CARNEIRO, 1995). Com base em Venturin et al. (2000), os aumentos expressivos no crescimento e qualidade das mudas têm sido alcançados pela correta adubação do substrato. Quando se opta pelo uso de solo, dá-se preferência às camadas mais profundas, os subsolos, por serem isentos de sementes e micro-organismos patogênicos. Os solos ou subsolos normalmente usados na formação de mudas apresentam reação ácida, são pobres em nutrientes e não atendem às exigências das espécies, entre eles, as diferentes classes de Latossolos e Argissolos, vários deles provenientes da região do cerrado (FURTINI NETO et al., 1999). Como exemplos, subsolo da camada de $20-40 \mathrm{~cm}$ de Latossolo Vermelho-Amarelo textura média usado por Braga et al. (1995) na produção de mudas de quatro espécies florestais, Argissolo Vermelho distrófico arênico da camada 0-20 cm usado por Lima et al. (2008) na produção de mudas de palmito (Euterpe edulis), Argissolo Vermelho-Amarelo, Latossolo Vermelho-Amarelo distrófico e Latossolo Vermelho-Amarelo álico, todos da camada de 20-100 cm, usados por Souza et al. (2008) na produção de mudas de bico-de-pato (Machaerium nictitans), subsolo abaixo de $20 \mathrm{~cm}$ de um Latossolo Vermelho-Amarelo distrófico usado por Cruz et al. (2011) na produção de mudas de canafístula (Peltophorum dubium), apresentaram valores de saturação por bases inferiores a $20 \%$ para os Latossolos e de $39 \%$ para os Argissolos e pH variando de 3,9 a 5,6. Esses autores verificaram que 
houve respostas à adubação nesses solos. As melhores mudas de bico-de-pato foram obtidas na saturação por bases de $60 \%$ no Argissolo, $70 \%$ no Latossolo distrófico e $40 \%$ no Latossolo álico (SOUZA et al., 2008). As mudas de canafístula responderam mais a aplicação de fósforo e magnésio e menos às doses de potássio e cálcio, sendo recomendadas as doses de $600 \mathrm{mg} \mathrm{dm}^{-3}$ de $\mathrm{P}, 2 \mathrm{mmol}_{\mathrm{c}} \mathrm{dm}^{-3} \mathrm{de} \mathrm{Mg}$, e doses mínimas de $50 \mathrm{mg} \mathrm{dm}^{-3}$ de $\mathrm{K}^{-} 8 \mathrm{mml}_{\mathrm{c}} \mathrm{dm}^{-3}$ de Ca (CRUZ et al., 2011). Esses trabalhos mostram que as diferenças de comportamento entre as espécies e os solos usados são geralmente ácidos, contêm altos teores de alumínio e baixos teores de nutrientes.

De acordo com Carneiro (1995), várias pesquisas têm procurado definir padrões adequados de fertilidade para produção de mudas. Esse autor mostra que bons resultados de pesquisas de nutrição e adubação já foram obtidos para os gêneros Pinus e Eucalyptus. Entretanto, para as espécies florestais nativas, os estudos são escassos e insuficientes, devido ao grande número de espécies que existem nos diferentes biomas brasileiros, sendo necessárias mais investigações, particularmente quando são usados substratos pobres em nutrientes (CRUZ et al., 2011).

A baixa fertilidade do solo está associada à escassez de bases trocáveis e ao excesso de alumínio e de manganês, condições que limitam o crescimento das plantas em geral (MALAVOLTA, 1987). Furtini Neto et al. (1999), trabalhando com Latossolo Vermelho-Escuro, distrófico, argiloso, fase cerrado tropical subcaducifólio, verificaram que a maior saturação de alumínio foi o fator ligado à acidez do solo, que mais limitou o crescimento e uso de nutrientes de mudas de quatro espécies arbóreas nativas, e a resposta em crescimento em função da correção da acidez do solo foi maior para as espécies de crescimento mais rápido. Além desses aspectos, os solos de baixa fertilidade apresentam, em geral, baixa disponibilidade de fósforo e baixo potencial de inoculo de micro-organismos benéficos para as mudas, como os fungos micorrízicos arbusculares (MELLO et al., 2008).

Mello et al. (2008), trabalhando com Neossolo Quartzarênico, verificaram que a aplicação de doses crescentes de fósforo, até $1000 \mathrm{mg} \mathrm{kg}^{-1}$, aumentou linearmente a altura de mudas de Acacia mearnsii (acácia-negra) não inoculadas com fungo micorrízicos, e quando não inoculadas também houve um amento, porém, explicada por equação de segundo grau e a máxima altura foi obtida entre as doses 100 e $500 \mathrm{mg} \mathrm{kg}^{-1}$.
De acordo com Tucci (1991), após a correção da acidez do solo, o fator nutricional que mais limita o crescimento das mudas é o baixo teor de fósforo disponível. Portanto, a prática da adubação fosfatada é recomendada na maioria dos casos de reflorestamento. Alguns autores constataram que as mudas respondem positivamente a doses de fósforo (DIAS et al., 1991; CHAVES et al., 1995; REIS et al., 1997). Várias espécies florestais nativas usadas em reflorestamento, principalmente para recuperação de áreas degradadas, têm respondido positivamente a doses relativamente altas de fósforo. Como exemplo, a dose de $360 \mathrm{mg} \mathrm{kg}^{-1}$ de $\mathrm{P}$ promoveu o maior crescimento das mudas tanto para canafístula (Peltophorum dubium) em Latossolo VermelhoAmarelo (SCHUMACHER et al., 2003), como para açoita-cavalo (Luehea divaricata) em Argissolo Vermelho-Amarelo (CECONI et al., 2006).

Considerando que as condições de ocorrência natural do sabiá se caracterizam por solos de acidez alta e baixos teores de nutrientes e que as mudas de espécies florestais nativas apresentam grande variabilidade quanto às suas exigências nutricionais (BRAGA et al., 1995; FURTINI NETO et al., 1999; SOUZA et al., 2008; CRUZ et al., 2011), estudos sobre aplicação de calcário e fósforo revestem-se de grande interesse prático.

Este trabalho teve por objetivo avaliar os efeitos de doses de calcário e fósforo na produção de mudas de sabiá (Mimosa caesalpiniifolia Benth.) sem acúleos, em ambiente protegido, usando como substrato o subsolo de um Latossolo VermelhoAmarelo distrófico psamítico.

\section{MATERIAL E MÉTODOS}

O presente experimento foi conduzido no período de 5 de julho a 28 de outubro de 2008, em casa de sombra coberta com tela de $50 \%$ de retenção de luz, localizada em área do Departamento de Fitotecnia do Centro de Ciências Agrárias da Universidade Federal do Piauí, município de Teresina, cujas coordenadas geográficas são $5^{\circ} 5^{\prime} 13^{\prime}$ ' de latitude Sul e $42^{\circ} 48^{\prime} 42^{\prime \prime}$ de longitude Oeste, a uma altitude de $72 \mathrm{~m}$ (BAPTISTA, 1981).

O clima é do tipo Aw' da classificação de Köppen (1949). A precipitação média é de $1324 \mathrm{~mm}$ e as médias de umidade relativa do ar e temperatura são de, respectivamente, $72,7 \% \mathrm{e}$ $28,5{ }^{\circ} \mathrm{C}$ (BASTOS e ANDRADE JÚNIOR, 2006). No período de condução do experimento (julho a outubro), as temperaturas médias das mínimas e 
máximas diárias variaram de 22 a $36{ }^{\circ} \mathrm{C}$ e a umidade relativa média foi de $58,8 \%$.

As sementes de sabiá (Mimosa caesalpiniifolia Benth.) foram procedentes de variedades da espécie sem acúleos, cultivadas num módulo experimental, localizado no Centro de Pesquisa do Trópico Semiárido (CPATSA) no município de Petrolina-PE. Selecionaram-se, com uso de peneiras, sementes dentro da classe de diâmetro de 3 a $4 \mathrm{~mm}$. Estas foram postas para germinar em bandejas de isopor com 128 células. A germinação das mesmas ocorreu onze dias após a semeadura. Procedeu-se a repicagem das plântulas para sacos de polietileno nas dimensões de $10,0 \mathrm{x}$ $23,0 \mathrm{~cm}$, contendo $2,0 \mathrm{~kg}$ de solo cada um.

Usou-se como substrato um Latossolo Vermelho-Amarelo distrófico psamítico, de textura média, horizonte A fraco, muito profundo, fase floresta secundária semicaducifólia, com topografia regular, suavemente ondulado, com declividade em torno de $5 \%$ (EMBRAPA, 2006). O solo foi coletado da camada de 40 a $70 \mathrm{~cm}$. A granulometria e os atributos químicos do subsolo foram determinados no Laboratório de Análise de Solos do Centro de Ciências Agrárias da Universidade Federal do Piauí, Teresina, PI. Os valores de $\mathrm{pH}$ foram determinados em $\mathrm{H}_{2} \mathrm{O}$, usando a relação 1:2,5. Cálcio, magnésio e alumínio foram extraídos com solução de $\mathrm{KCl}$ $1 \mathrm{~mol} \mathrm{~L}^{-1}$. Os dois primeiros foram determinados por espectrometria de absorção atômica e o alumínio por volumetria. $\mathrm{O}$ fósforo, o potássio e o sódio foram extraídos com o extrator Mehlich-1 e determinados por colorimetria $(\mathrm{P})$ e fotometria de chama $(\mathrm{K}$ e $\mathrm{Na})$. A acidez total $(\mathrm{H}+\mathrm{Al})$ foi determinada por volumetria, após extração com solução de acetato de cálcio $0,5 \mathrm{~mol} \mathrm{~L}^{-1} \mathrm{pH} \mathrm{7,0.} \mathrm{A} \mathrm{capacidade} \mathrm{de} \mathrm{troca}$ catiônica $(\mathrm{T})$ foi obtida pela soma das bases trocáveis (SB) com a acidez total (EMBRAPA, 1997). Os resultados obtidos são apresentados na Tabela 1.

Foram aplicados cinco tratamentos de fósforo, sem aplicação e mais quatro doses de $\mathrm{P}$, todos na presença e ausência de calcário, em um arranjo fatorial 2 x 5 . A parcela experimental foi constituída de três mudas, cada uma em um recipiente. As doses de calcário e fósforo foram determinadas para $6 \mathrm{~kg}$ de solo da parcela. A quantidade de calcário foi calculada para elevar a saturação por bases de $22 \%$ para $50 \%$. O calcário apresentou $85 \%$ de PRNT, contendo $32 \%$ de $\mathrm{CaO}$ e $14 \%$ de $\mathrm{MgO}$. O solo permaneceu incubado por trinta dias, mantendo o teor de água ao redor de $70 \%$ da sua capacidade máxima de retenção de água, com base no método da porcentagem de saturação: razão entre a diferença do peso de um cilindro (bloco) de solo saturado e peso do bloco seco a $105^{\circ} \mathrm{C}$ pelo volume do cilindro (espaço poroso) (EMBRAPA, 1997).

Após a incubação, o solo foi seco e adubado com 0, 30, 60, 90 e $120 \mathrm{mg} \mathrm{kg}^{-1}$ de P, usando-se como fonte o superfosfato triplo $\left(41 \%\right.$ de $\left.\mathrm{P}_{2} \mathrm{O}_{5}\right) \mathrm{em}$ pó.

Foram aplicados como adubação de base $200 \mathrm{mg} \mathrm{kg}^{-1}$ de $\mathrm{N}$, parcelados em quatro vezes, e $150 \mathrm{mg} \mathrm{kg}^{-1}$ de $\mathrm{K}$, em dose única, aplicada simultaneamente ao adubo fosfatado, vinte dias antes da repicagem das plântulas. Trinta dias depois, aplicou-se solução de micronutrientes de modo a adicionar 2,0 $\mathrm{mg} \mathrm{kg}^{-1}$ de $\mathrm{Zn}$; $0,5 \mathrm{mg} \mathrm{kg}^{-1}$ de $\mathrm{Cu}$; $0,5 \mathrm{mg} \mathrm{kg}^{-1}$ de B; $1,5 \mathrm{mg} \mathrm{kg}^{-1}$ de Mn e $0,1 \mathrm{mg} \mathrm{kg}^{-1} \mathrm{de}$ Mo, empregando, respectivamente, sulfato de zinco, sulfato de cobre, ácido bórico, cloreto de manganês

TABELA 1: Características físicas e químicas das amostras de solo, coletadas na camada de 40 a $70 \mathrm{~cm}$, usadas na produção das mudas antes da aplicação dos tratamentos.

TABLE 1: Physical and chemical characteristics of soil samples, collected from 40 to $70 \mathrm{~cm}$ layer, used for the production of the seedlings before the application of the treatments.

\begin{tabular}{|c|c|c|c|c|c|c|c|}
\hline \multicolumn{6}{|c|}{ Composição granulométrica (Dispersão com NaOH $1 \mathrm{~mol} \mathrm{~L}^{-1}$ ) $\mathrm{g} \mathrm{kg}^{-1}$} & \multirow{3}{*}{$\begin{array}{l}\text { Classe } \\
\text { textural }\end{array}$} & \multirow{3}{*}{$\begin{array}{c}\text { Densidade do } \\
\text { solo } \\
\left(\mathrm{kg} \mathrm{dm}^{-3}\right)\end{array}$} \\
\hline Areia grossa & Areia fina & Silte & & Argila & & & \\
\hline$(2-0,20 \mathrm{~mm})$ & $(0,20-0,05 \mathrm{~mm})$ & $(0,05-0,002 \mathrm{~mm})$ & & $<0,002 \mathrm{~mm}$ & & & \\
\hline 250 & 470 & 140 & & 140 & & $\begin{array}{l}\text { Areia } \\
\text { franca }\end{array}$ & 1,37 \\
\hline $\mathrm{pH}_{\mathrm{H} 2 \mathrm{O}}$ & $\mathrm{Mg}^{2+(1)}$ & $\mathrm{Na}^{+(2)}$ & $\mathrm{Al}^{3+(1)}$ & $\mathrm{H}+\mathrm{Al}^{(3)}$ & $\mathrm{T}$ & V & $\mathrm{P}^{(2)}$ \\
\hline -------- & ------------------- & $-\mathrm{mmol}_{\mathrm{c}} \mathrm{dm}^{-3}--$ & - & ----------- & 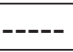 & $\%$ & $\mathrm{mg} \mathrm{dm}^{-3}$ \\
\hline 5,5 & 0,8 & 0,8 & 6,9 & 49 & 63 & 22 & 1 \\
\hline
\end{tabular}

Em que: ${ }^{(1)}=$ Extrator: $\mathrm{KCl} 1 \mathrm{~mol} \mathrm{~L}^{-1}{ }^{(2)}=$ Extrator: Mehlich-1; (3) $=$ Extrator: acetato de cálcio $0,5 \mathrm{~mol} \mathrm{~L}^{-1} ; \mathrm{SB}=$ soma de bases; $\mathrm{T}$ = capacidade de troca catiônica; e $\mathrm{V}=$ saturação por bases. 
e molibdato de amônio. As doses dos nutrientes foram estabelecidas com base nas recomendações de Malavolta (1980) e Novais et al. (1991), mas foram feitos ajustes que consideraram as características do solo, a espécie, o volume de solo em cada recipiente e o tempo de condução do experimento.

Os tratamentos foram dispostos em um delineamento em blocos ao acaso com quatro repetições. Ao final de 115 dias foram feitas avaliações de: altura das mudas com uma régua graduada em centímetros; diâmetro a $1,0 \mathrm{~cm}$ do coleto, medido com paquímetro digital de $0,05 \mathrm{~mm}$ de precisão; número de folhas; área foliar, obtida com medidor de área foliar digital, modelo LI3100 com resolução de $1,0 \mathrm{~mm}^{2}$; e quantidades de matéria seca da parte aérea e raízes, após secagem a $65^{\circ} \mathrm{C}$ em estufa com circulação de ar forçado até que atingissem peso constante.

Os dados obtidos foram submetidos à análise de variância pelo teste F. Os efeitos das doses de fósforo e de calcário, na ausência e presença de calcário, foram estudados por análise de regressão polinomial. Diante de dois ou mais modelos com coeficientes significativos, optou-se por aquele que apresentou maior $\mathrm{R}^{2}$ e, quando o componente de segundo grau da regressão foi significativo, foi determinado o ponto de máximo da equação, anulando-se a sua derivada primeira, e calculada a dose de fósforo para obtenção de $90 \%$ dos valores máximos estimados das variáveis estudadas (CRUZ et al., 2011). Os procedimentos estatísticos foram feitos com o uso do programa desenvolvido por Barbosa e Maldonado Júnior (2011).

\section{RESULTADOS E DISCUSSÃO}

O efeito do fósforo foi observado para todas as variáveis de crescimento das mudas (Tabela 2). Houve efeito isolado da calagem na altura e no número de folhas das mudas. Para o número de folhas, houve efeito da interação fósforo $\mathrm{x}$ calagem. Houve efeito linear e quadrático do fósforo para todas as variáveis. Os resultados da interação fósforo $\mathrm{x}$ calagem para as variáveis estudadas e as equações que melhor explicaram a variação dos dados foram apresentados e ilustrados na Figura 1.

TABELA 2: Médias e análises de variância, de regressão para altura (H), diâmetro (D), número de folhas (NF), área foliar (AF), matéria seca da parte aérea (MSPA) e das raízes (MSR) de mudas de Mimosa caesalpiniifolia em função de doses de fósforo com $(\mathrm{C} / \mathrm{C})$ e sem $(\mathrm{S} / \mathrm{C})$ calagem e suas interações, 115 dias após a repicagem.

TABLE 2: $\quad$ Medium values and variance analysis, regression for height $(H)$, diameter $(D)$, number of leaves (NF), leaf area (AF), shoot (MSPA) and roots (MSR) dry matter of Mimosa caesalpiniifolia seedlings as a function of phosphorus doses with $(\mathrm{C} / \mathrm{C})$ and without $(\mathrm{S} / \mathrm{C})$ liming and their interactions, 115 days after transplanting.

\begin{tabular}{|c|c|c|c|c|c|c|c|c|c|c|c|c|}
\hline \multirow{3}{*}{$\begin{array}{l}\begin{array}{l}\text { Doses de P } \\
\left(\mathrm{mg} \mathrm{kg}^{-1}\right)\end{array} \\
\end{array}$} & \multicolumn{12}{|c|}{ Médias dos tratamentos } \\
\hline & \multicolumn{2}{|c|}{$\mathrm{H}(\mathrm{cm})$} & \multicolumn{2}{|c|}{$\mathrm{D}(\mathrm{mm})$} & \multicolumn{2}{|c|}{ NF } & \multicolumn{2}{|c|}{$\mathrm{AF}\left(\mathrm{cm}^{2}\right)$} & \multicolumn{2}{|c|}{$\operatorname{MSPA}(\mathrm{g})$} & \multicolumn{2}{|c|}{ MSR (g) } \\
\hline & $\mathrm{C} / \mathrm{C}$ & $\mathrm{S} / \mathrm{C}$ & $\mathrm{C} / \mathrm{C}$ & $\mathrm{S} / \mathrm{C}$ & $\mathrm{C} / \mathrm{C}$ & $\mathrm{S} / \mathrm{C}$ & $\mathrm{C} / \mathrm{C}$ & $\mathrm{S} / \mathrm{C}$ & $\mathrm{C} / \mathrm{C}$ & $\mathrm{S} / \mathrm{C}$ & $\mathrm{C} / \mathrm{C}$ & $\mathrm{S} / \mathrm{C}$ \\
\hline 0 & 4,28 & 3,75 & 1,66 & 1,35 & 2,00 & 1,42 & 8 & 2 & 0,12 & 0,04 & 0,25 & 0,15 \\
\hline 30 & 15,41 & 16,91 & 2,67 & 2,96 & 8,83 & 7,58 & 625 & 497 & 2,65 & 2,57 & 1,75 & 1,73 \\
\hline 60 & 19,91 & 25,42 & 3,40 & 3,66 & 8,91 & 10,25 & 870 & 1214 & 4,22 & 5,51 & 3,11 & 2,89 \\
\hline 90 & 16,32 & 22,89 & 3,52 & 3,60 & 10,41 & 9,16 & 556 & 724 & 4,51 & 5,11 & 3,20 & 2,99 \\
\hline 120 & 21,97 & 25,69 & 4,05 & 4,23 & 10,42 & 9,08 & 884 & 857 & 5,71 & 6,74 & 3,48 & 3,99 \\
\hline Causas de & \multicolumn{12}{|c|}{ Valores de F (significâncias) } \\
\hline Variação & \multicolumn{2}{|c|}{$\mathrm{H}$} & \multicolumn{2}{|c|}{$\mathrm{D}$} & \multicolumn{2}{|c|}{ NF } & \multicolumn{2}{|c|}{$\mathrm{AF}$} & \multicolumn{2}{|c|}{ MSPA } & \multicolumn{2}{|c|}{ MSR } \\
\hline Doses de P (P) & \multicolumn{2}{|c|}{$71,58^{* *}$} & \multicolumn{2}{|c|}{$166,04 * *$} & \multicolumn{2}{|c|}{$116,99 * *$} & \multicolumn{2}{|c|}{$29,01 * *$} & \multicolumn{2}{|c|}{$54,52 * *$} & \multicolumn{2}{|c|}{$51,57^{* *}$} \\
\hline Calagem (Cal) & \multicolumn{2}{|c|}{$15,83^{* *}$} & \multicolumn{2}{|c|}{$2,03 \mathrm{~ns}$} & \multicolumn{2}{|c|}{$4,60^{*}$} & \multicolumn{2}{|c|}{$1,15 \mathrm{~ns}$} & \multicolumn{2}{|c|}{$3,58 \mathrm{~ns}$} & \multicolumn{2}{|c|}{$0,00 \mathrm{~ns}$} \\
\hline Interação (PxCal) & \multicolumn{2}{|c|}{$2,37 \mathrm{~ns}$} & \multicolumn{2}{|c|}{$2,38 \mathrm{~ns}$} & \multicolumn{2}{|c|}{$3,11 *$} & \multicolumn{2}{|c|}{$1,62 \mathrm{~ns}$} & \multicolumn{2}{|c|}{$0,92 \mathrm{~ns}$} & \multicolumn{2}{|c|}{$0,59 \mathrm{~ns}$} \\
\hline Blocos & & & 3, & & & & & & & & 0,36 & \\
\hline Resíduo (QM) & & & 0,0 & & & & 4297 & 2554 & & & 0,3 & \\
\hline$\overline{\mathrm{CV}}$ & & & & & & & & & & & 23 & \\
\hline & 208 & $5 * *$ & 586, & & 302 & & & & 196 & $2 * *$ & 185 & $5 * *$ \\
\hline Reg. Linear & $\mathrm{R}^{2}=$ &, 73 & $\mathrm{R}^{2}=$ &, 88 & $\mathrm{R}^{2}=$ &, 65 & & 0,53 & $\mathrm{R}^{2}=$ &, 90 & $\mathrm{R}^{2}=$ & 0,90 \\
\hline & & & & & 140 & & & & & & 16,2 & \\
\hline Reg. Quadrática & $\mathrm{R}^{2}=$ &, 91 & $\mathrm{R}^{2}=$ &, 96 & $\mathrm{R}^{2}=$ &, 95 & & 0,80 & $\mathrm{R}^{2}=$ &, 97 & $\mathrm{R}^{2}=$ & \\
\hline
\end{tabular}

Em que: $n s=$ não significativo $(\mathrm{P}>0,05) ; *=$ Significativo a $5 \%(\mathrm{P}<0,05) ; \mathrm{e} * *=$ Significativo a $1 \%(\mathrm{P}<0,01)$. 

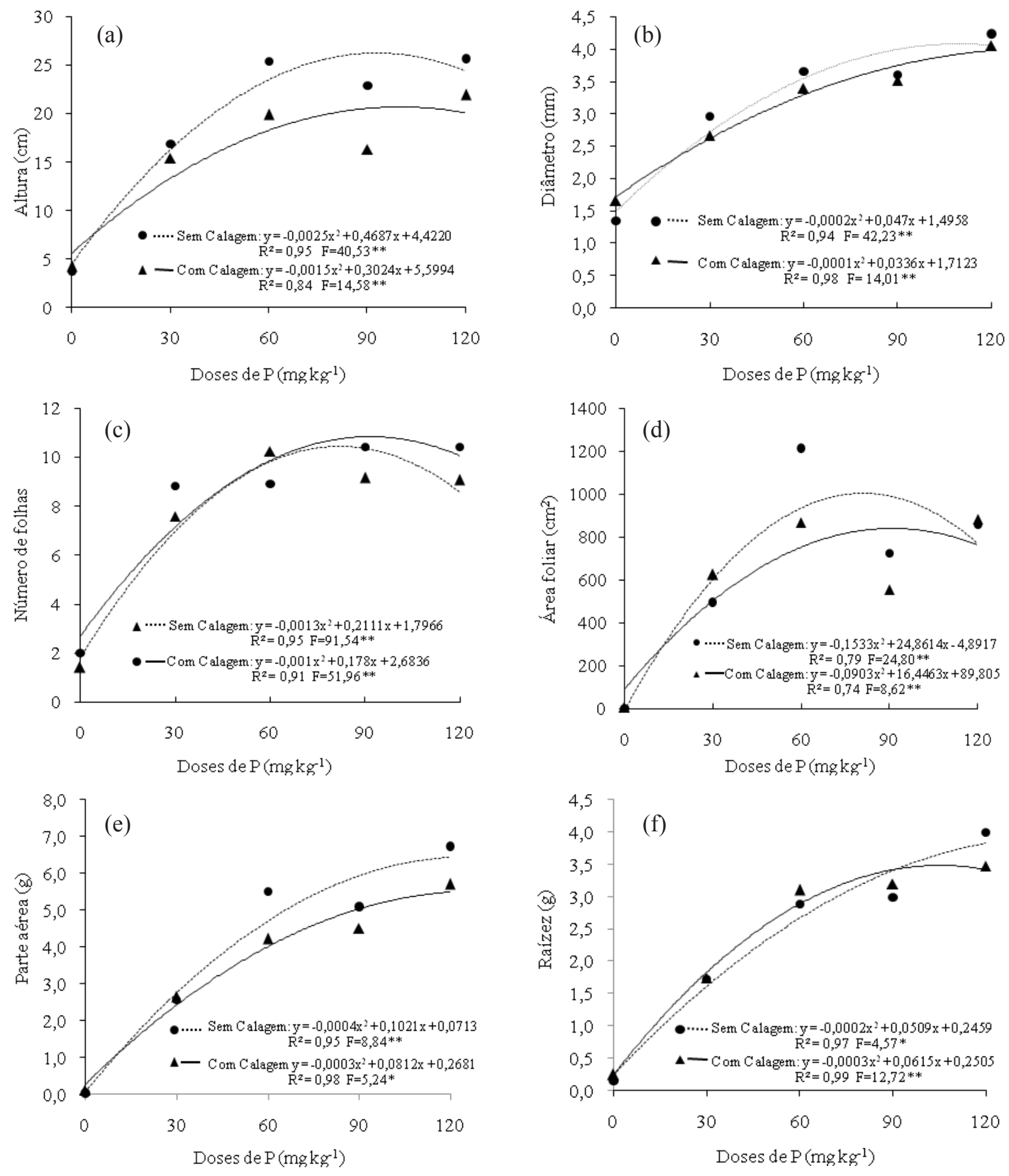

FIGURA 1: Crescimento em altura (a), diâmetro (b), número de folhas (c), área foliar (d), produção de matéria seca da parte aérea (e) e das raízes (f) de mudas de sabiá (Mimosa caesalpiniifolia Benth.) em função de doses de $\mathrm{P}$, com e sem calagem, aos 115 dias após a repicagem.

FIGURE 1: Grow in height (a), diameter (b), number of leaves (c), leaf area (d), shoot (e) and roots (f) dry matter production of Mimosa caesalpiniifolia Benth. Seedlings in function of doses of $\mathrm{P}$, with and without liming in 115 days after transplanting. 
O crescimento das mudas que receberam fósforo e calcário foi menor do que as que receberam apenas fósforo. Essa resposta pode ser explicada pelo fato do solo apresentar originalmente os teores 5,5 e $6,9 \mathrm{mmol}_{\mathrm{c}} \mathrm{dm}^{-3}$ respectivamente de $\mathrm{Ca}$ e $\mathrm{Mg}$, considerados médios de acordo com as classes propostas por Raij (1991) e pelo fato da espécie sabiá ser tolerante a solos com elevada acidez (MENDES, 1989). Vale et al. (1996) estudando o desenvolvimento de raízes de mudas de 14 espécies florestais nativas e de Eucalyptus grandis em vasos contendo subsolo de Latossolo VermelhoEscuro submetido a diferentes tratamentos para elevar o $\mathrm{pH}$, teor de cálcio, magnésio e reduzir o teor de alumínio trocável, verificaram que as mudas de sabiá, entre outras espécies pioneiras, foram altamente tolerantes à acidez do solo e à toxidez pelo alumínio. Esses autores observaram que os teores no subsolo do tratamento testemunha de 1,20 e $0,5 \mathrm{mmol}_{\mathrm{c}} \mathrm{dm}^{-3}$, respectivamente de $\mathrm{Ca}$ e $\mathrm{Mg}$, não limitaram o crescimento das raízes das mudas de sabiá. Alguns trabalhos, como esse, que envolvem a calagem em condições de viveiro com eucalipto e espécies florestais nativas indicam baixa demanda de cálcio e magnésio durante seu crescimento inicial. Souza et al. (2008) verificaram que nenhuma das características de crescimento das mudas da espécie pioneira bico-de-pato (Machaerium nictitans Benth.) apresentou resposta significativa diante da elevação da saturação por bases do substrato Argissolo Vermelho-Amarelo. Esses autores também atribuíram a não resposta aos teores iniciais de 17,4 e 1,7 $\mathrm{mmol}_{\mathrm{c}} \mathrm{dm}^{-3} \mathrm{de} \mathrm{Ca}$ e $\mathrm{Mg}$, respectivamente, e a saturação por bases de 39,4\%. Nesse mesmo tipo de solo com 16 e 1,0 $\mathrm{mmol}_{\mathrm{c}} \mathrm{dm}$ ${ }^{3}$, respectivamente de $\mathrm{Ca}$ e $\mathrm{Mg}$, Cruz et al. (2011) não verificaram efeito da aplicação de cálcio na forma de $\mathrm{CaCO}_{3}$ nas características de crescimento de canafístula (Peltophorum dubium Taub.), porém, houve resposta à aplicação de magnésio na forma de $\mathrm{MgCO}_{3}$, e recomendam a dose para que o solo apresente 5,0 $\mathrm{mmol}_{c} \mathrm{dm}^{-3}$ de $\mathrm{Mg}$. Ao elevar a saturação por bases de um Latossolo Vermelho distrófico de $24 \%$, condição natural, para $40 \%$, $50 \%, 60 \%$ e $70 \%$, Gomes et al. (2004) observaram que esses aumentos não interferiram no crescimento de mudas de angico-branco (Anadenanthera colubrina (Vell.) Brenan) e consideram que essa falta de resposta pode estar relacionada ao fato de que os teores no solo de 9 e $4 \mathrm{mmol}_{\mathrm{c}} \mathrm{dm}^{-}$ 3, respectivamente de $\mathrm{Ca} \mathrm{e} \mathrm{Mg}$, tenham sido suficientes para suprir as necessidades das mudas.
Artur et al. (2007) ao avaliarem os efeitos de doses de esterco bovino e calcário na formação de mudas de guanandi (Calophyllum brasiliense Cambess.), não observaram efeito do calcário para todas as variáveis de crescimento e atribuíram os teores de $\mathrm{Ca}=5,0 \mathrm{mmol}_{\mathrm{c}} \mathrm{dm}^{-3}$ e $\mathrm{Mg}=2,0 \mathrm{mmol}_{\mathrm{c}} \mathrm{dm}^{-3}$, já existentes no subsolo usado como substrato, suficientes às mudas.

Os modelos de segundo grau foram os que melhor explicaram os efeitos do fósforo nas características avaliadas. Sem calagem, os pontos de máximo valor das variáveis dependentes, calculados a partir das equações de regressão apresentadas na Figura 1, foram: altura de $26,2 \mathrm{~cm}$ com a aplicação de $94 \mathrm{mg} \mathrm{kg}^{-1}$ de P (Figura 1a), diâmetro de 4,26 cm com a aplicação de $118 \mathrm{mg} \mathrm{kg}^{-1}$ de $\mathrm{P}$ (Figura $1 \mathrm{~b}$ ), área foliar de $1003 \mathrm{~cm}^{2}$ com $81 \mathrm{mg} \mathrm{kg}^{-1}$ de $\mathrm{P}$ (Figura 1d), biomassa da parte aérea de $6,45 \mathrm{~g}$ com $120 \mathrm{mg} \mathrm{kg}^{-1}$ de P (Figura 1e) e biomassa de raízes de 3,14 g com $120 \mathrm{mg} \mathrm{kg}^{-1}$ de P (Figura 1f). Com relação à interação fósforo $\mathrm{x}$ calagem que ocorreu para número de folhas, verificou-se que o maior valor dessa variável foi obtido com $99 \mathrm{mg} \mathrm{kg}^{-1}$ de $\mathrm{P}$ na presença de calagem (Figura 1c).

Sendo assim, as doses de fósforo que proporcionaram as máximas respostas de altura, diâmetro, área foliar, biomassa da parte aérea e raízes, variaram de 81 a $120 \mathrm{mg} \mathrm{kg}^{-1}$ de $\mathrm{P}$, independente da adição de calcário (Figura 1). Os valores máximos dessas variáveis foram obtidos em média na dose de $107 \mathrm{mg} \mathrm{kg}^{-1}$ de P. No entanto, com aplicação de 56 a $87 \mathrm{mg} \mathrm{kg}^{-1}$ de $\mathrm{P}$, com média de $72 \mathrm{mg} \mathrm{kg}^{-1}$, é possível obter $90 \%$ das máximas respostas para as mesmas variáveis.

Esse efeito significativo do fósforo no crescimento das mudas de Mimosa caesalpiniifolia está de acordo com as observações de Resende et al. (1999). Esses autores avaliaram o comportamento de cinco espécies florestais pioneiras, entre elas sabiá, e quatro não pioneiras, em resposta a doses de fósforo em Latossolo Vermelho-Escuro distrófico, originalmente com $1 \mathrm{mg} \mathrm{dm}^{-3} \mathrm{de} \mathrm{P}$, e verificaram que as espécies pioneiras apresentaram crescimento mais rápido e foram mais responsivas ao fornecimento de fósforo do que as não pioneiras. Encontraram um valor de $592 \mathrm{mg} \mathrm{dm}^{-3}$ de $\mathrm{P}$ de recomendação de adubação fosfatada para se obter, em média, $90 \%$ dos máximos valores de altura, diâmetro, biomassa de raízes e da parte aérea de mudas de sabiá, valor bem mais alto ao do presente estudo, e ressalvando que a unidade de dose usada por esses autores foi com base no volume de solo e não massa. 
Com relação à espécie secundária inicial, a variação de produção de biomassa de mudas de paineira (Ceiba speciosa St. Hill.) também foi explicada por equação de segundo grau em função da aplicação de fósforo, sendo que a dose para obtenção de $90 \%$ da produção máxima de matéria seca da parte aérea foi de $267 \mathrm{mg} \mathrm{dm}^{-3}$ (FERNANDES et al., 2000). Schumacher et al. (2003) verificaram que, em Argissolo Vermelho-Amarelo, mesmo com teor de fósforo de 29,5 $\mathrm{mg} \mathrm{dm}^{-3}$ (extrator Mehlich-1), a dose relativamente alta de $360 \mathrm{mg} \mathrm{kg}^{-1}$ resultou no maior crescimento das mudas de canafístula (Peltophorum dubium).

Gomes et al. (2008) verificaram que, para o crescimento de mudas de garapa (Apuleia leiocarpa J.F.Macbr.) em Latossolo Vermelho distrófico, apresentando originalmente $\mathrm{pH}=5,1$ e $\mathrm{V} \%=24$, as doses estimadas de fósforo que proporcionaram $90 \%$ da produção máxima de matéria seca da parte aérea variaram de $54 \mathrm{mg} \mathrm{dm}^{-3}$ no solo com $60 \%$ de saturação por bases a $191 \mathrm{mg} \mathrm{dm}^{-3}$ no solo com $40 \%$ de saturação por bases. Os autores concluíram que para a produção de mudas de garapa deve ser feita a aplicação de $54 \mathrm{mg} \mathrm{dm}^{-3}$ de $\mathrm{P}$, juntamente com a aplicação de calcário que eleve a saturação por bases a $60 \%$. Nesse caso, a correção da acidez pode se refletir em economia de adubo fosfatado, o que não ocorreu neste trabalho. Valeri et al. (2003), ao avaliarem o efeito do fósforo no crescimento de mudas de jenipapo (Genipa americana L.), verificaram que a maior biomassa do caule das mudas foi obtida com os teores de P no solo de 45 e $59 \mathrm{mg} \mathrm{dm}^{-3}$ em Neossolos Quartzarênicos com baixos teores de argila ( $9 \%$ e $14 \%$ ), a exemplo do solo usado na presente pesquisa.

Esses trabalhos mostram que as espécies florestais apresentam grande variação no comportamento diante da adubação fosfatada. Santos et al. (2008) verificaram, além desse fato, que as espécies pioneiras foram mais eficientes em produzir matéria seca da parte aérea e na absorção de fósforo do que as não pioneiras. A variação de resposta à adubação fosfatada, além de ocorrer entre espécies, ocorre dentro da mesma espécie em função das características genéticas e dos atributos físicos e químicos do solo. De acordo com Fernández et al. (2008) solos argilosos tendem a reter o fósforo do solo na forma não lábil, dificultando a sua disponibilidade às plantas. A magnitude da retenção de $\mathrm{P}$ em solos tropicais, em resposta à sua mineralogia, considera a presença de matéria orgânica (ALMEIDA et al., 2003), tipo de argila e grau de cristalização dos oxi- hidróxidos de $\mathrm{Fe}$ e Al. O fósforo é um elemento pouco móvel no solo e seu suprimento para as raízes é efetuado principalmente pelo processo de difusão, o qual depende da umidade do solo e da superfície radicular (GAHOONIA et al., 1994). Por sua vez, a umidade do solo interfere diretamente no desenvolvimento das raízes, influenciando direta e indiretamente no fornecimento de fósforo para as plantas (MACKAY e BARBER, 1985).

É importante a realização de trabalhos que definam os níveis críticos de cálcio e magnésio no solo, pois a calagem para mudas de espécies produtoras de madeira é necessária não só para correção de acidez, mas para o fornecimento desses dois nutrientes que são fundamentais para formação do caule.

Os resultados mostraram que o Latossolo Vermelho-Amarelo distrófico psamítico estudado neste trabalho, na sua condição química original sem receber calcário, possui teores de cálcio e magnésio suficientes para produção de mudas de sabiá (Mimosa caesalpiniifolia Benth.). Entretanto, a espécie foi responsiva à adubação fosfatada.

\section{CONCLUSÕES}

Nas condições do presente trabalho, a calagem não é necessária para produção de mudas de sabiá (Mimosa caesalpiniifolia Benth.).

Com aplicação de, em média, 72 a $107 \mathrm{mg} \mathrm{kg}^{-1}$ de P no subsolo usado como substrato obtém-se, respectivamente, de 90 a $100 \%$ dos máximos rendimentos de altura, diâmetro, área foliar, biomassa da parte aérea e raízes de mudas de sabiá.

\section{REFERÊNCIAS BIBLIOGRÁFICAS}

ALMEIDA, J. A.; TORRENT, J.; BARRÓN, V. Cor de solo, formas de fósforo e adsorção de fosfatos em Latossolos desenvolvidos de basalto do extremo-sul do Brasil. Revista Brasileira de Ciência do Solo, Viçosa, v. 27, n. 6, nov./dez., p. 985-1002, 2003.

ARTUR, A. G.; CRUZ, M. C. P.; FERREIRA, M. E. Esterco bovino e calagem para formação de mudas de guanandi. Pesquisa Agropecuária Brasileira, Brasília, v. 42, n. 6, p. 843-850, jun. 2007.

BAPTISTA, J. G. Geografia física do Piauí. Teresina: COMEPI. 1981. 182p.

BARBOSA, J. C.; MALDONADO JÚNIOR, W. AgroEstat: sistema para análises estatísticas de ensaios agronômicos, versão 1.1.0.626, 2011. 
Jaboticabal: FCAV - Departamento de Ciências Exatas, 2011.

BASTOS, E. A.; ANDRADE JÚNIOR, A. S. Dados agrometeorológicos para o município de Teresina, PI (1980-2004). Teresina: Embrapa Meio-Norte, 2006. 36 p.

BRAGA, F. A. et al. Exigências nutricionais de quatro espécies florestais. Revista Árvore, Viçosa, v. 19, n. 1, p. 18-31, 1995.

BRAGA, R. Plantas do nordeste, especialmente do Ceará. 3. ed. Mossoró: ESAM 1976, p. 435-436 (ESAM Coleção Mossoroense, 42).

CARNEIRO, J. G. A. Produção e controle de qualidade de mudas de espécies florestais. Curitiba: UFPR-FUPEF, 1995. 451p.

CECONI, D. E. et al. Crescimento de mudas de açoita cavalo (Luehea divaricata Mart.) sob influência da adubação fosfatada. Cerne, Lavras, v. 12, n. 3, p. 292-299, jul./set. 2006.

CHAVES, L. F. C. et al. Crescimento de mudas de jacarandá da Bahia (Dalbergia nigra (Vell.) Fr. Allem.) em resposta a inoculação com fungos micorrízicos vezículo-arbusculares em diferentes níveis de fósforo no solo. Revista Árvore, Viçosa, v. 19, n. 1, p. 32-49, 1995.

CRUZ, C. A. F. et al. efeito de macronutrientes sobre o crescimento e qualidade de mudas de canafístula cultivadas em latossolo vermelhoamarelo distrófico. Revista Árvore, Viçosa, v. 35, n. 5, p. 983-995, set./out. 2011.

DIAS, L. E.; ALVAREZ, V. H. V.; JUCKSCH, I. Formação de mudas de taxi-branco (Sclerolobium paniculatum Vogel em resposta a calcário e fósforo. Pesquisa Agropecuária Brasileira, Brasília, v. 26, n. 1, p. 69-70, 1991.

EMBRAPA, Centro nacional de pesquisa de solo. Sistema brasileiro de classificação de solos. 2. ed. Rio de Janeiro, 2006. 412 p.

EMBRAPA. Centro nacional de pesquisa de solo. Manual de métodos de análise do solo. 2. ed. Rio de Janeiro, 212 p. 1997.

FERNANDES, L. A. et al. Crescimento inicial, níveis críticos de fósforo e frações fosfatadas em espécies florestais. Pesquisa Agropecuária Brasileira, Brasília, v. 35, n. 6, p. 1191-1198, jun. 2000.

FERNÁNDEZ R., I. E. et al. Reversibilidade de fósforo não-lábil em solos submetidos à redução microbiana e química. ii - extrações sucessivas do fósforo pela resina de troca aniônica. Revista Brasileira de Ciência do Solo, Viçosa, v. 32, n. 6, nov./dez., p. 2319-2330, 2008.
FURTINI NETO, A. E. et al. Acidez do solo, crescimento e nutrição mineral de algumas espécies arbóreas, na fase de muda. Cerne, Lavras, v. 5, n. 2, p. 1-12, 1999.

GAHOONIA, T. S.; RAZA, S.; NIELSEN, N. E. Phosphorus depletion in the rhizosfere as influenced by soil moisture. Plant and Soil, Dordrecht, v. 159, n. 2, p. 213-218, 1994.

GOMES, K. C. O. et al. Crescimento de mudas de garapa em resposta à calagem e ao fósforo. Revista Árvore, Viçosa, v. 32, n. 3, p. 387-394, maio/jun. 2008.

GOMES, K. C. O. et al. Influência da saturação por base e do fósforo no crescimento de mudas de angico-branco. Revista Árvore, Viçosa, v. 28, n. 6, p. 785-792, nov./dez. 2004.

GONÇALVES, C. A.; FERNANDES, M. M.; ANDRADE, A. M. Celulose e carvão vegetal de Mimosa caesalpiniifolia Benth. (sabiá). Floresta e Ambiente, Seropédica, v. 6, n. 1, p. 51-58, jan./dez. 1999.

JACOMINE, P. K. T. Levantamento exploratórioreconhecimento de solos no estado do Piaúi. Rio de Janeiro: EMBRAPA-SNLCS/SUDENE-DRN. 1986. $782 \mathrm{p}$.

KÖPPEN, W. Das geographische system der klimate. Handbuch of klimatologie, Berlin: Bortraeger, 1949.

LIMA, L. S. H.; FRANCO, E. T. H.; SCHUMACHER, M. V. Crescimento de mudas de Euterpe edulis Martius em resposta a diferentes doses de fósforo. Ciência Florestal, Santa Maria, v. 18, n. 4, p. 461-470, out./dez. 2008.

LORENZI, H. Árvores brasileiras: manual de identificação e cultivo de plantas arbóreas nativas do Brasil. 3. ed. Nova Odessa: Instituto Plantarum, 2000. $351 \mathrm{p}$.

MACKAY, A. D.; BARBER, S. Soil moisture effect on root growth and phosphorus uptake by corn. Agronomy Journal, Madison, v. 77, p. 519-523, 1985.

MALAVOLTA, E. Elementos de nutrição mineral de plantas. São Paulo: Agronômica Ceres, 1980. $254 \mathrm{p}$.

MALAVOLTA, E. Manual de calagem e adubação das principais culturas. São Paulo: Agronômica Ceres, 1987. $496 \mathrm{p}$.

MELLO, A. H. et al. Influência de substratos e fósforo na produção de mudas micorrizadas de Acacia mearnsii De Wild. Ciência Florestal, Santa Maria, v. 18, n. 3, p. 321-327, jul./set. 2008.

MENDES, B. V. Sabiá (Mimosa caesalpiniifolia 
Benth.): valiosa forrageira arbórea e produtora de madeira das caatingas. Mossoró: ESAM, 1989. 31 p. (Coleção Mossoroense, 660 Série B).

NOVAIS, R. F.; NEVES, J. C. L.; BARROS, N. F. Ensaio em ambiente controlado. In: OLIVEIRA, A. J.; GARRIDO, W. E.; ARAÚJO, J. D.; LOURENÇO, $\mathrm{S}$. (Coord.). Métodos de pesquisa em fertilidade do solo. Brasília: Embrapa-SEA, 1991. p.189-253. (Embrapa-SEA. Documentos, 3).

RAIJ, B. van. Fertilidade do solo e adubação. São Paulo: Agronômica Ceres, Associação Brasileira para a Pesquisa da Potassa e do Fósforo, 1991. 343 p.

RAMALHO, P. E. Sabiá Mimosa caesalpiniifolia. Colombo: Embrapa Florestas, nov. 2007. 10 p. (Circular técnica, 135).

REIS, M. G. F. et al. Exigências nutricionais de mudas de Jacarandá da Bahia (Dalbergia nigra (Vell.) Fr. Allem. Produzidas em dois níveis de sombreamento. Revista Árvore, Viçosa, v. 21, n. 4, p. 63-471, 1997.

RESENDE, A. V. et al. Crescimento inicial de espécies florestais de diferentes grupos sucessionais em resposta a doses de fósforo. Pesquisa Agropecuária Brasileira, Brasília, v. 34, n. 11, p. 2071-2081, nov. 1999.
RIBASKI, J. et al. Sabiá (Mimosa caesalpiniifolia): árvore de múltiplo uso no Brasil. Colombo: Embrapa Florestas, 2003. 4 p. (Comunicado técnico, 104).

SCHUMACHER, M. V.; CECONI, D. E.; SANTANA, C. A. Influência de diferentes doses de fósforo no crescimento de plantas de canafístula (Peltophorum dubium (Sprengel) Taubert. Boletim de Pesquisa Florestal, Colombo, n. 47, p. 99-114, jul./dez. 2003

SOUZA, P. H. et al. Influência da saturação por bases do substrato no crescimento e qualidade de mudas de Machaerium nictitans (Vell.) benth. Revista Árvore, Viçosa, v. 32, n. 2, p. 193-201, mar./abr. 2008.

TUCCI, C. A. F. Disponibilidade de fósforo em solos da Amazônia. 1991. 142 f. Tese (Doutorado em Solos e Nutrição de Plantas) - Universidade Federal de Viçosa, Viçosa, 1991.

VALERI, S. V.; PUERTA, R.; CRUZ, M. C. P. Efeitos do fósforo do solo no desenvolvimento inicial de Genipa americana L. Scientia Florestalis, Piracicaba, n. 64, p. 69-77, dez. 2003.

VENTURIN, R. P. et al. Efeito da relação Ca:Mg do corretivo no desenvolvimento e nutrição mineral de mudas de aroeira (Myiracroduon urundeuva Fr. All.). Cerne, Lavras, v. 6, n. 1. p. 30-39, 2000. 